\title{
New teaching methods - Using computer technology in physics, mathematics and computer science
}

\author{
Morten Brekke, Per Henrik Hogstad \\ University of Agder, Norway
}

\begin{abstract}
In 2001 the University of Agder started a project whose aim was to increase the number of students applying for engineering studies, as well as hopefully improve their skills in mathematics and physics. The project known as parAbel developed e-learning courses for upper level students (from ages $16-19$ years old) in mathematics and physics. These courses (six in all) could also be used in our own engineering recruitment study programme at our own university. As the project developed, we also programmed advanced simulations and a computer based graphic calculator, all under the name SimReal. SimReal is a tool that is meant to bee a supplement to traditional teaching, using visualization and interactivity to explain difficult topics. Subsequently I have used parAbel and SimReal in both physics and mathematics courses at my university for approximately 5 years. The effects of using computer technology in my teaching so far have been very rewarding for both my students and me This have been shown in previous works. Last year we developed an additional part of SimReal called SimVideo. SimVideo is an interactive learning tool which is integrated within SimReal. It contains videos of lectures, simulations, problem solving and applications. SimVideo is so new that we have not yet developed much content in physics and mathematics, but Per Henrik Hogstad have briefly tried it out in a course given in computer science. This autumn 2009 SimVideo was tested in DAT201 Algorithms and data structures. The feedback from students on this course was very good. We are now trying out and developing new content for our physics course in the bachelor programme.
\end{abstract}

\section{Introduction}

In the early days of the parAbel-project [1], University of Agder [2] had a licensing agreement with Heriot-Watt University in Edinburgh and was inspired by their Scholar-programme [3]. A report [4] from the University of Strathclyde on be half of the Scottish Executive Education Department, concludes that students who where user of the
Scholar programme, exhibit an overall better performance than do other students in the same subjects. The report also states that the recruitment levels increased in technological study programmes. Students especially liked working with interactivity, simulations and problems-solving.

By varying the presentation we are able to reach more people who will become engaged in the learning process [5]. New Multimedia Technology gives the opportunity to create variations. "Students now are from the Nintendo generation. They need to see things moving to understand and process information." [6]. Too meet this generation of young students, I thought why not try to meet them at the half way. Keeping what I believe is good and importance methods, such as laboratory work and manual problem-solving. I needed to find good computer-aided programs for this. Working with the parAbel-group at our university, we developed ourselves animations, simulations and a "virtual laboratory", for this purpose [7]. We also developed an online graphically PC-computer based calculator that could work together with other simulations in SimReal [8]. SimReal is an interactive simulation and learning tools in science. The tool is intended to be a supplement to traditional teaching in areas where the issues are difficult to explain, visualize or perform. SimReal includes calculator and measurement tools so that users can interact with the tool.

Other studies [9] show that if a teacher can organize a learning arena that incorporates different working methods for gaining knowledge, the results will improve. With this background in mind I started trying out different approaches on my own students. I began experimenting with different learning arenas inn 2003, and have made several adjustments since then. Similar and larger research projects have been completed at the by University of Colorado, PheT [10]. The results [11] from using parAbel and SimReal in Physic course FYS002 has been presented in detail earlier at the LICE 2009 conference in London [12]. In this work, I will still present the main points and conclusions from the earlier work. 
Since this work Per Henrik Hogstad has developed a new application called SimVideo, giving us the new version called SimReal+ [13]. SimVideo are interactive learning tools integrated with SimReal which contains video-lectures, video-simulations, interactive simulations, task review and applications with opportunities for continuous exchange between these different elements without loosing the focus in the temporarily abandoned item. SimVideo can be integrated in different learning arenas and video modules, with the possibility of including interactive learning and the building of joint virtual laboratories in real time.

\section{Innovation and relevance}

Previous studies [14] and [15] suggested improvements for students using computer-aided programs and different learning arenas. It is my experience that students like the variation found by using different learning techniques.

\subsection{Innovation and relevance teaching in physics FYS002}

To extend variation in my teaching, I used animations to explain difficult theoretical subjects in my lectures in the Physics course FYS002. It makes it a lot easier to explain how a transistor works if an animation shows the inside of it. Then I could let the students work with problems using more advanced simulations on that subject.

To prepare my students before manual laboratory work, I can give them exercises using a "virtual laboratory" that we developed. This helps students both to know what to do and give them more understanding when entering the laboratory. Figure 1 shows an animation and a simulation in the "virtual laboratory" of a transistor.

The last thing I have tried out in FYS002 is to let my student do exercises with the "virtual laboratory”, and then write a report. The report must be sent electronically into our learning management system (LMS), which is Fronter, to be evaluated and approved. This could be exercises that is impossible to perform "live" or is too dangerous to perform in an ordinary laboratory. We have developed several simulations that fit our ordinary laboratory-exercises.

There is a lot of work ahead for teachers to find the correct resources and right programs on the computer, but the reward of finding these resources can be great.

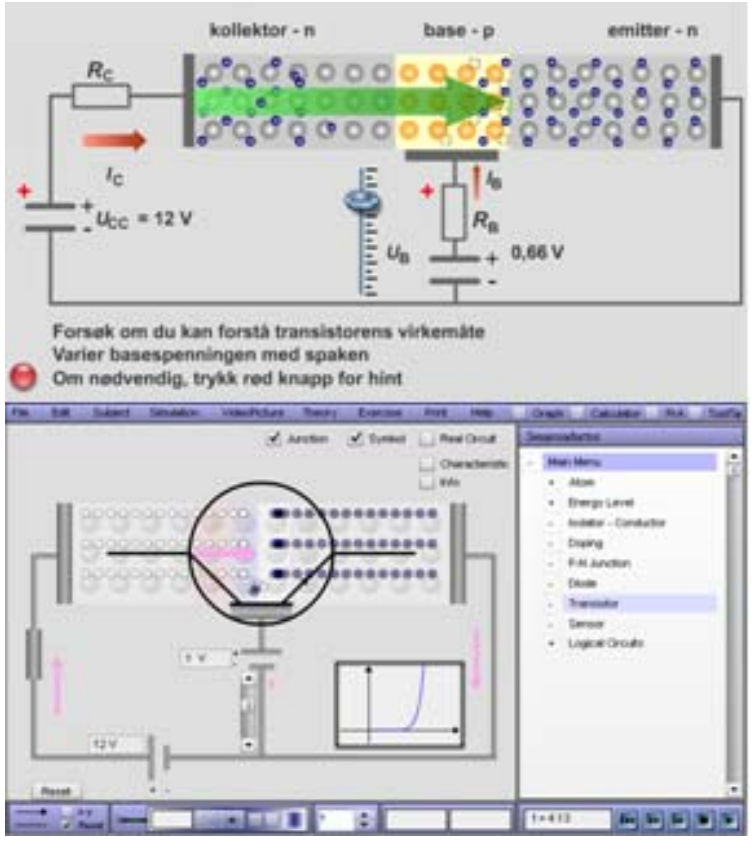

Figure 1. Animation (top) and simulation (bottom) showing the interior of a transistor. In the "Virtual laboratory" students can investigate how the transistor works

After all, isn't it having more satisfied and skilled students, what we all want? Of course, if the teacher herself/himself has good computer skills, this gives students a great advantage. Findings by Oersted at PheT [16] say that interactive simulations can be uniquely powerful educational tools, and must be carefully designed, tested and used in pedagogically effective ways.

\subsection{Innovation and relevance teaching in computer science DAT201.}

In the autumn semester of 2009 Per Henrik Hogstad tested out, for the first time SimVideo in the computer science course DAT201 - Algorithms and data structures. The SimVideo learning tool gives the students lots of opportunities in addition to the ordinary classic lectures and exercise sessions. SimVideo is a large resource bank where students can find videos of lectures, videos of simulations, try it yourself simulations and lots more.

Students can choose between two versions of lectures, both with voice that is read by the lecturer. One version shows written theory review or 'live' video lecture, se Figure 2. The other one shows theory review preferentially using PowerPoint slides, se Figure 3. In both of these videos the speech of the lecturer are as close up to the regular lecture as possible. Students can jump directly from the videolecture over to interactive simulations that deal with the theme of the lecture to try for themselves, se Figure 4. The simulations also have video support. Students can always jump back and forth between 
the video lectures and simulations. They will then return to where they last left the respective application.

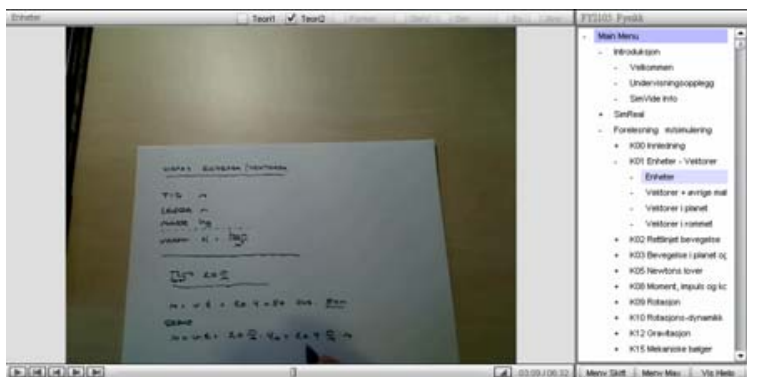

Figure 3. SimVideo shows written theory review or 'live' video lecture

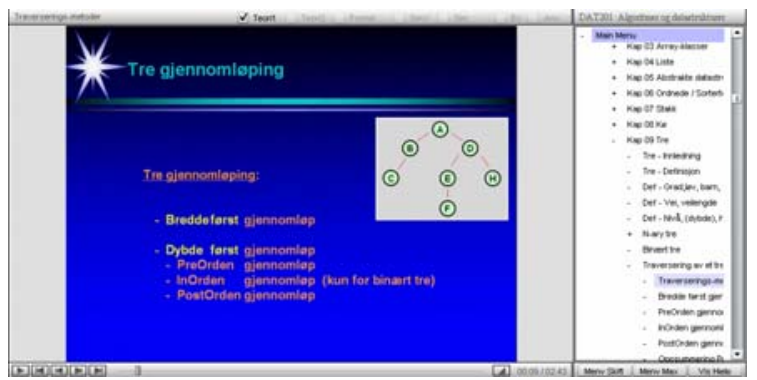

Figure 4. SimVideo shows theory review using PowerPoint slides

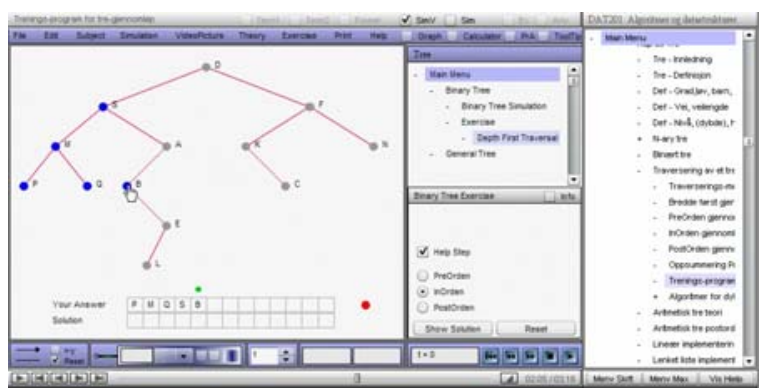

Figure 5. SimVideo shows simulations students can try for themselves

SimVideo is designed so that every lecturer should be able to easily create their own video lectures themselves. There is of course some work to make the videos, but have you first made them, reuse benefits great. One of the main points of SimVideo is that students can sit for themselves and get the repetition of the lectures whenever they feel for it. SimVideo is also designed so that during work on a simulation, students will be able with a single click to jump right into a SimVideo-lecture covering that topic one is working on.

One big question was raised before SimVideo was adopted on DAT201, would students still meet at the regular lectures? By posting lectures on video, they had the opportunity to sit on their own to see them. The experience made from this course showed that students showed up to the same extent as before.

\section{Results}

There have been ongoing surveys in both courses to check on student progress, satisfaction and desire for further applications. This helps us to improve the tool from course to course, and give us new ideas for further development.

\subsection{Results from FYS002}

I have found out, after using computers in my classroom over the past six years, that it is a very positive and fulfilling experience. Let me first start by giving you some interesting data. As part of insure and keep up a good quality to our university student programs, we have repeatedly evaluation at the end of each course. Let me bring you some results of the evaluation of one of the subjects that I teach. FYS002 is a Physics course where I let students work with theoretical problems, calculation problems, exercises on computer (has to be delivered electronically the LMS), "virtual laboratory" and manual physics laboratory work. The evaluation is done in our LMS electronically with several questions about different part of the course such as;

1. How satisfied are you with the teaching given in this course?

2. Which work form has given you the best learning experience?

3. How satisfied are you with the feedback on your work?

4. How much of organized teaching have you taken part in?

5. How many hours per week have you in averaged used on this course?

6. Consider your previous knowledge, how do you consider the level of difficulty?

7. How do you consider the level of difficulty of the literature in this course?

8. Are you happy with the form of evaluation and exam in this course?

9. Comments by students if any.

I have been monitoring answers giving from year 2003 to 2007. At that point this form of evaluation ended here at the university. We now evaluate courses in a different way and not electronically as before. 2004 was the first year that computer technology was used on this course. Adjustments and improvements have taken place every year to find the right amount of how much computers should be used. In 2004 approximately 50\% of student's workload was problem-solving on computers. The rest of the time students worked with theory, manual problems-solving and manual laboratory work. Feedback from the evaluation in 2004, especially from question 9: "comments by students if any" suggested, surprisingly for me, many students thought it was too much focus on computer work. So I adjusted workloads after this, to $1 / 3$ problem- 
solving on computers, $1 / 3$ theory and manual problem-solving and 1/3 manual laboratory work. After this adjustment no more comments about too much computer work have been mentioned. Comments now usually are about how much they appreciate variation and different techniques learned during the course.

I will not go in detail on each of the bullet point above, but concentrate on what I think is most interesting. I was especially interested to get results from questions 1 and 5 , so I made my own investigation on these two points. I must emphasize that there is only one year, 2003 where no computers was being used. Also it is important to notice that only about $25-35 \%$ of the students did take their time to do the evaluation. However these results clearly suggest that students are more satisfied and work harder after computers made their way into this course.

Let us start with question 1, how satisfied are the students. Students could pick their opinion from six levels, ranked from 1-bad to 6-excellent. The results are shown in table 1.

Table 1. Results from question 1 from 2003 to 2007, given in percentage

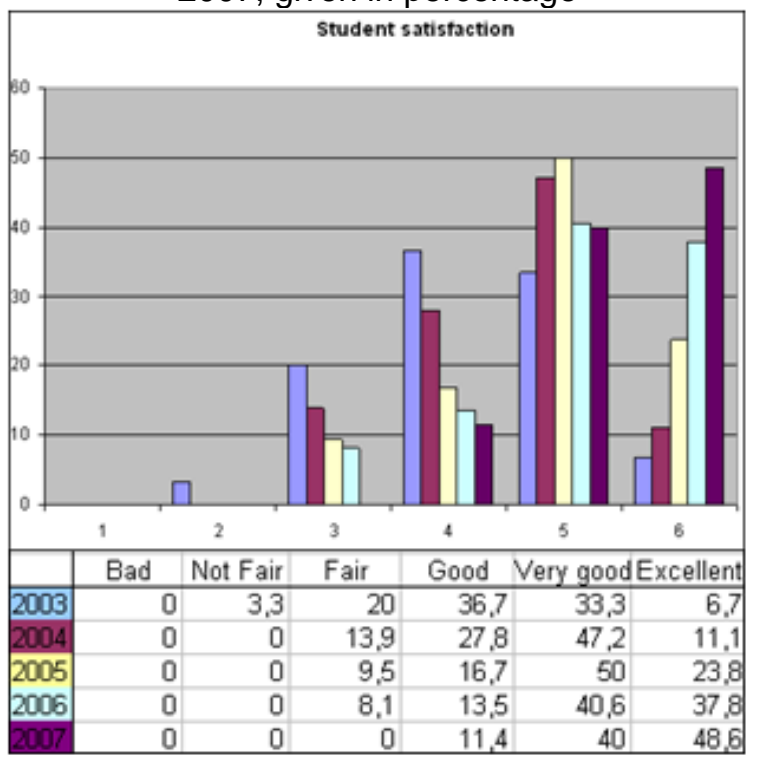

The results indicate that students are more satisfied with my teaching now that I use computer technology rather than before. Comments from students also suggest that they get a better understanding of physics, the more I visualize with computers. They also thinks the variation of lectures, manual problems-solving, computer-work and manual laboratory work make the subject "less boring". Actually many of my students try out, on their own many other simulations that is not part of the curriculum.

I feel now that I have found the right balance between, lectures, pc-work, manual problem-solving and laboratory work. Moreover using parAbel and SimReal is no problem for students. I use approximately 1 hour at the start of each semester to show how each program operates. Young students generally have good computer skills, so once you get them started they quickly get to work. I have experienced few technical problems, although a supportive university IT helpdesk does come in handy.

Next interesting question is number 5, how many hours per week do the students work. In this course FYS002 students should put in 6 to 8 hours per week as a minimum. FYS002 is a pre-course for students who lack competence in Physics. These students take part here to prepare them for university physics. Many of these are not the strongest candidates in mathematics and physics. In this evaluation students could pick their workload from six levels, ranked from 6 ( 0 to 4 hours a week) to 1 (14 ore more hours per week). Table 2 shows how large percentage of students who use 8 or more hours on average per week on the subject. As you can see more than half of the students use more than 8 hours a week in 2007 , compared to just under quarter of 2003. As we see the increase is significant.

Table 2. How many students have worked more than 8 hours per week (average) from 2003 to 2007

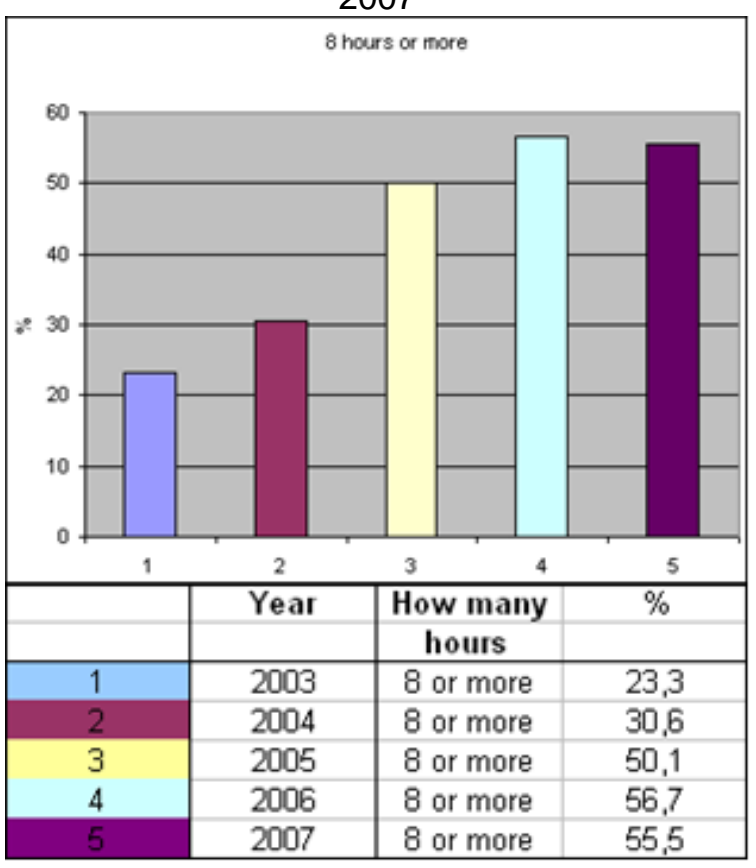

Since 2003, my evaluation of FYS002 (Physicscourse) suggests that students now have doubled their time spent on the course. If we take a look at how many students that have used more than 8 hours a week in average (which is what we recommend as a minimum), we se that hours spent has increased by more than a factor of 2 . 
The performance of students on exams has also been better. Grades have improved by nearly one level. Furthermore students are more satisfied with the current situation now that computers are being used. I have experienced that I can still assign the same amount of laboratory work and manual problem-solving to students, and then add computerbased assignments, without hearing them complain about having too great a workload.

One drawback for me is that it has been a lot of work the put things together. I made several "lacydogs" (manuals) for my students. This prevents too much questions from students about how things work. I experienced that students tends to think it is easier to ask, rather than to find out them selves. It also gives me some extra work to evaluate and give feedback to students. But I am getting better every year at this, and have made routines that make my workload less every year. But then again, my students are happy and perform better, so extra efforts are rewarding.

\subsection{Results from DAT201}

The computer science course DAT201 (Algorithms and data structures) is given each autumn by Per Henrik Hogstad. This autumn 2009 SimVideo was tested in a similar way as I have done in FYS002. During the DAT201-course a mid-term review and a final evaluation were done. At the midterm review there were given 15 questions:

1. SimVideo is a positive element as a supplement to traditional teaching.

2. SimVideo gives large variations in a learning process.

3. How great is the usefulness for you to use SimVideo-lectures in 'easy' subjects?

4. How great is the usefulness for you to use SimVideo-lectures in 'difficult' subjects?

5. How great is the usefulness for you to use SimVideo simulations in 'easy' subjects?

6. How great is the usefulness for you to use SimVideo simulations in 'difficult' subjects?

7. How great is the usefulness for you to use SimVideo-self training in 'easy' subjects?

8. How great is the usefulness for you to use SimVideo-self training in 'difficult' subjects?

9. How great is the usefulness for you to use a tool like SimVideo to see a practical application of a particular issue?

10. SimVideo provides very useful effect of your program and algorithm-understanding.

11. SimVideo will be helpful in the review of assignments / examination preparation for the exam.

12. SimVideo is easy to use.
13. Advantages of diagnostic program (program that follows you in your thinking / choices until you see possible error choices).

14. Advantages of video conferencing with fellow students and teachers.

15. How would you grade the usefulness on different use of SimVideo:

a) At the regular study days

b) If sick leave

c) When having other kind of work in the study period (you are in full or partial work outside the university).

At the final evaluation 6 more questions was added:

16. Video qualities in SimVideo are of sufficiently good quality.

17. To what extent is it important to you that the lecturer is shown 'live' in a SimVideolecture?

18. Do you use SimVideo often in the review of a theme in DAT201?

19. How important is the 10 -second rewind ability in SimVideo?

20. Is the line speed in which you use SimVideo sufficient to avoid 'video jam' in the video?

21. How do you consider the possibility of SimVideo to alternate between lectures, simulation, self training and applications?

Students were also encouraged to suggest changes and improvements of SimVideo.

The mid-term evaluation gave these results. 25 students participated and gave their answers. Each student considered the questions and answered them by giving marks on a scale of 1 to 10 (10 best, 1 worst) Table 3 shows how students answered at the mid-term evaluation.

Table 3. Answers from the mid-term evaluation (Autumn 2009).

\begin{tabular}{|c|r|r|r|r|r|r|r|r|r|r|r|}
\hline Quest & 1 & 2 & 3 & 4 & 5 & 6 & 7 & 8 & 9 & 10 & Sum \\
\hline 1 & & & & & 1 & & 1 & 6 & 3 & 14 & 25 \\
\hline 2 & & & & & 3 & 1 & 8 & 5 & 1 & 7 & 25 \\
\hline 3 & 1 & 1 & 6 & 2 & 5 & 1 & 5 & 1 & & 3 & 25 \\
\hline 4 & & & & & 1 & 3 & 4 & 6 & 3 & 8 & 25 \\
\hline 5 & & 2 & 4 & 1 & 5 & 4 & 4 & 1 & & 4 & 25 \\
\hline 6 & & & & & 2 & 1 & 3 & 2 & 8 & 9 & 25 \\
\hline 7 & & 4 & 2 & & 5 & 1 & 7 & 1 & 2 & 3 & 25 \\
\hline 8 & & & & & 2 & & 4 & 6 & 6 & 7 & 25 \\
\hline 9 & & & & & 3 & 1 & 1 & 9 & 4 & 7 & 25 \\
\hline 10 & & & 3 & 1 & 3 & 1 & 2 & 4 & 5 & 6 & 25 \\
\hline 11 & & & 1 & 2 & 3 & 1 & 5 & 3 & 2 & 7 & 24 \\
\hline 12 & & & & 1 & 3 & 4 & 6 & 7 & 2 & 2 & 25 \\
\hline 13 & & & & & 1 & 1 & 1 & 8 & 5 & 9 & 25 \\
\hline 14 & & 1 & 2 & 2 & 2 & 7 & 4 & 4 & 2 & & 24 \\
\hline $15 a$ & & & 2 & 2 & 4 & 5 & 4 & 3 & 2 & 3 & 25 \\
\hline $15 b$ & & & & & & & 1 & 4 & 2 & 18 & 25 \\
\hline $15 \mathrm{c}$ & & & & & & & 6 & 2 & 2 & 15 & 25 \\
\hline
\end{tabular}

To quickly get an overview of the evaluation, you can see the trend in chart 1 . 
Chart 1. Answers from the mid-term evaluation (Autumn 2009). The color of the columns is related to the color number in Table 3

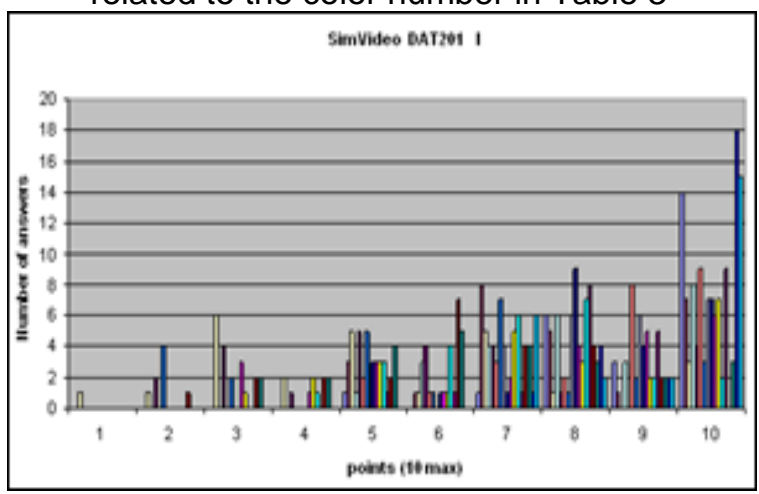

Although the graph is small, we can clearly see that the chart is 'top heavy'. This indicates that most students have given top or well above average score on each question. Although the feedback from the mid-term evaluation and the regular student contact was good, we were anxious to see how the final evaluation would turn out. Often, students get excited about the introduction of new tools, but after a period of use, everyday life settle in and things will turn out boring for them.

So what did the final evaluation say? 22 students participated and gave their answers. Table 4 shows how students answered at the final evaluation.

Table 4. Answers from the final evaluation (Autumn 2009).

\begin{tabular}{|c|r|r|r|r|r|r|r|r|r|r|r|}
\hline Quest & 1 & 2 & 3 & 4 & 5 & 6 & 7 & 8 & 9 & 10 & um \\
\hline 1 & & & & & & 1 & 3 & 2 & 3 & 13 & 22 \\
\hline 2 & & & 1 & 1 & 2 & 1 & 5 & 6 & & 5 & 21 \\
\hline 3 & & 1 & 2 & 3 & 5 & 2 & 3 & 4 & 1 & 1 & 22 \\
\hline 4 & & & & & 2 & 1 & 3 & 5 & 4 & 7 & 22 \\
\hline 5 & & & 4 & 4 & 3 & 2 & 3 & 4 & & 2 & 22 \\
\hline 6 & & & & & 2 & 1 & 3 & 3 & 6 & 7 & 22 \\
\hline 7 & 1 & 2 & 1 & 1 & 4 & 1 & 6 & 3 & 2 & 1 & 22 \\
\hline 8 & & & & 1 & 3 & & 4 & 3 & 5 & 6 & 22 \\
\hline 5 & & & & & & 2 & 1 & 7 & 5 & 7 & 22 \\
\hline 10 & & & 1 & 1 & & 3 & 5 & 6 & 1 & 5 & 22 \\
\hline 11 & & & & & 2 & 1 & 3 & 6 & 6 & 4 & 22 \\
\hline 12 & & & 1 & & 1 & 4 & 7 & 4 & 3 & 2 & 22 \\
\hline 13 & & & & & 5 & 1 & 8 & 2 & 1 & 4 & 21 \\
\hline 14 & 1 & 4 & 1 & 3 & 5 & & 4 & 2 & & 1 & 21 \\
\hline $15 a$ & & & 1 & 2 & 1 & 8 & 1 & 3 & 2 & 4 & 22 \\
\hline $15 b$ & & & & & & & & 3 & 4 & 15 & 22 \\
\hline $15 \mathrm{c}$ & 1 & & & 1 & 3 & 1 & 2 & 3 & 2 & 9 & 22 \\
\hline 16 & & & & 1 & 2 & 2 & 4 & 7 & 2 & 4 & 22 \\
\hline 17 & 3 & 2 & 2 & 1 & 6 & 3 & 2 & 2 & 1 & & 22 \\
\hline 18 & 2 & 1 & & 3 & 3 & 2 & 5 & 2 & 1 & 3 & 22 \\
\hline 19 & & & & 1 & & & 2 & 8 & 1 & 10 & 22 \\
\hline 20 & & & & & 1 & 1 & 5 & 2 & 3 & 10 & 22 \\
\hline 21 & & & 1 & & 1 & 2 & 2 & 6 & 2 & 8 & 22 \\
\hline
\end{tabular}

And to quickly get an overview of this evaluation also, you can see the trend in chart 2. At this evaluation 6 more questions were added.
Chart 2. Answers from the final evaluation (Autumn 2009). The color of the columns is related to the color number in Table 4

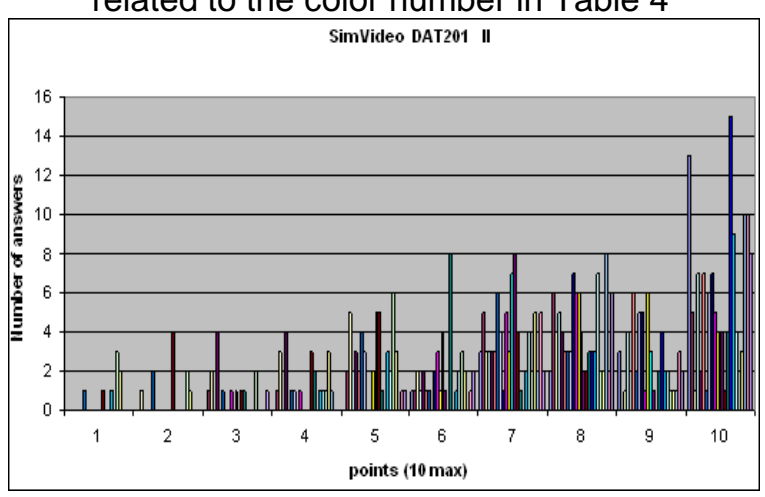

Again the graph is small, but we can clearly see that the chart is still 'top heavy'. This indicates that most students still thinks SimVideo is a great help in the course DAT201. I will not go in detail on each question, but if we go deeper and look at the results of some questions, it provides a basis for some interesting issues.

Question 1: SimVideo is a positive element as a supplement to traditional teaching.

At this question over half of the students gave 10 points at both mid-term and final evaluations. 92\% at mid-term and $82 \%$ at final gave 8 points or more.

Question 3 to 8: How great is the usefulness for you to use SimVideo-lectures/simulations/self training in 'easy'/'difficult' subjects?

These questions also show an interesting issue. Questions 3, 5 and 7, shows that the desire for SimVideo is not so great in subject that can be considered as 'easy'. While questions 4, 6 and 8, suggest that the desire for SimVideo is greater in subject that can be considered as 'difficult'.

Question 9: How great is the usefulness for you to use a tool like SimVideo to see a practical application of a particular issue?

At this question $80 \%$ of the students at mid-term and $86 \%$ of the students at final gave 8 points or more. This is something students have requested for many other different subjects also.

Question 10: SimVideo provides very useful effect of your program and algorithm-understanding. At this question $68 \%$ of the students at mid-term and $77 \%$ of the students at final gave 7 points or more. This indicates that the tool helps them to get a better understanding of theory in the course.

Question 11: SimVideo will be helpful in the review of assignments / examination preparation for the exam. At this question $71 \%$ of the students at mid-term and $86 \%$ of the students at final gave 7 points or more. This indicates that the tool will help students to prepare for exams and hopefully also perform better. 
Question 13: Advantages of diagnostic programs (programs that follows you in your thinking/choices until you see possible error choices).

Students are also here positive for such applications. Hopefully we will develop more diagnostic programs in the future.

Question 14: Advantages of video conferencing with fellow students and teachers.

This was a point where we as teachers may have thought the interest would be great, but the evaluation shows little interest among students for this.

Question 15: How would you grade the usefulness on different use of SimVideo.

This question is divided into three sub-points. Interesting to note is that the students see SimVideo as an important and helpful tool when they are home with illness or when they have full-or part-time job outside the university.

Question 18 (only at final evaluation): Do you use SimVideo often in the review of a theme in DAT201?

We had perhaps thought that more students would use the tool to review the content, but the evaluation showed that the responses were evenly distributed on the points scale.

Question 19 (only at final evaluation): How important is the 10-second rewind ability in SimVideo?

Being able to fast forward and back with 10 second steps is important. To be able to move easily between different parts of the lecture makes it easier to use and the educational effect is better.

Question 20 (only at final evaluation): How do you consider the possibility of SimVideo to alternate between lectures, simulation, self training and applications?

At this question $73 \%$ of the students gave 8 points or more. As mentioned earlier in this work, it seems that students like the variety of multiple teaching methods. With more available choices students will also have greater opportunities to find the appropriate learning methods that suit them.

\section{Conclusions}

By integrating computer-based work into the classroom in Physics, my experience is that students are more satisfied, spend more time studying, and most importantly perform better. Having modern facilities such as up-to-date computers, good internet connections and computer support at the university is also important. It takes time to test and use interactive simulations in pedagogically effective ways. You need to carefully investigate what works and what does not work, and then fit it into your own pedagogically platform. However I am not convinced that everybody should take computers into their classroom. If teachers are not motivated or do not feel comfortable with them, they will probably do more harm than good.

Together with ongoing development of the additional tool SimVideo, new and completely different possibilities opens up for me as a teacher. I can spend less time in lectures trying to explain how the tool works. Help on using different tools can be made by producing video and audio in SimVideo. It is our goal that making videos will be so simple that even teachers with less computer experience can produce their own videos in any subject areas, not only in science. We believe that giving students many different opportunities to acquire academic material gives them a better opportunity to learn more. But we want to emphasize that we do not believe that use of computer tools should replace traditional teaching. Data tools are a supplement to the ordinary teaching. Lectures and dialogue between teacher and student is still fundamental to achieve a good learning arena for students. We should not ignore that there are students who likes auditory and reading. These students must also be offered good learning environments. We should neither forget that traditional problem-solving also is very important. There are still written exams in most subjects, so students need training in how to solve exams questions.

If we look further forward in time, I think digital exams will appear in more subjects. Such exams are demanding both in terms of appropriate data tools, avoid computer breakdown, wireless communication, security and how to avoid cheating among students. Feedbacks from students from our evaluations on SimVideo are good and I think good tools should be taken into use in ordinary exams. Students who learn to master a good learning tool should be able to use this also at the final exam or end evaluation. Of course the most important and central issue is to be able to understand theoretical and practical content in a course, being able to master a computer-based tools is no point in itself. We must distinguish between how to acquire theoretical and practical subject material, and how to use computer tools. Computer tools are useless if they do not have educational effects to improve learning of theoretical and practical material.

The spring of 2010 SimVideo will be tested on our course Physic for engineering, FYS105. This is a larger group of students, approximately 300. Much larger than any groups the tool has been tested on so far. This is also on a higher level than the Physics course FYS002. We will here investigate and evaluate how students use, and what they think about SimVideo. This will be presented in works to come. We will also test this program on higher advanced mathematics courses, but this testing has not yet started. We have great expectations that SimVideo will enrich physics teaching at our university. SimVideo is still a young product and has great 
development potential. To conclude our experiences in the form of key words we will bring up the following:

- Students see the usefulness of the tool.

- Students seem to like to work with the tool.

- Students found the tool as a positive addition to ordinary teaching.

- Students found the tool particularly suitable in difficult subject areas.

- $\quad$ Students found the tool is particularly suited to see practical applications.

\section{References}

[1] parAbel. Grimstad, Webadress: http://www.parabel.no/

[2] University of Agder Webadress: http://www.uia.no/

[3] SCHOLAR. Webadresse: http://scholar.hw.ac.uk/

[4] Dr Kay Livingstone and Dr Rae Condie, The Quality in Education Centre, University of Strathclyde, Faculty of Education. Evaluation of Phase Two of the SCHOLAR Programme, Final report.April 2004.

[5] Teaching to Variation in Learning, Brian Hayden, PhD http://www.brown.edu/Departments/Italian_Studies/dweb/ pedagogy/variation.

[6] Nutrition and Animation: Students Can’t Get Enough A profile of Dr. Liz Applegate by Autumn Bouck, http://ittimes.ucdavis.edu/jan2001/applegate.html

[7] Ola T Aas. "parAbel is a Norwegian success - it delivers Mathematics and Physics at High School level on the Internet and illustrates how animations can bring quality to e-learning”. Higher Colleges of Technology Abu Dhabi, UAE, November 19 - 21, 2005, http://www.admc.hct.ac.ae/emel2005/presenters.aspx?Ola \%20T.\%20Aas

[8] Brekke, M and Hogstad, P H. SimReal et interaktivt arbeidsverktøy i fysikk, matematikk og statistikk. Det virtuelle laboratorium til bruk i parAbel. Article (in norwegian) at the Norwegian Networked Universityconference "En ny hverdag". HiA, Grimstad, 13 - 14 march 2006.

[9] Lester, F. K. \& William D. On the purpose of mathematics education research: Making productive contributions to policy and practice, University of Strathclyde, In L. English (Ed.), International handbook and research in mathematics education (pp. 489-506). Mahweh, NJ: Lawrence Erlbaum Associates, 2002.

[10] PhET Interactive Simulations, University of Colorado: Webadress: http://phet.colorado.edu/about/index.php

[11] Brekke, Morten, Effects of bringing computer technology in physics and mathematics into the classroom, London International Conference on education (LICE 2009), November 9-12, 2009, London, UK.

ISBN: 978-0-9564263-0-7
[12] London International Conference on education (LICE 2009), November 9-12, 2009, London, UK. http://www.liceducation.org/LICE-2009/

[13] SimVideo+, Per Henrik Hogstad. http://www.parabel.no/sim/sim_info/simreal/simreal_no/In fo.htm

[14] Brekke, M., parAbel-prosjektet, bruk av multimedia i e-læringskurs til å fremme læring av og interesse for matematikk. Fra ide til interaktive løsninger. Article (in norwegian) at the Norwegian Networked Universityconference "Nettbasert laring i høyere utdanning". HiNT, Levanger, 14 - 15 mars 2005.

ISBN 82-7456-416-2

[15] Brekke, Morten. Innføring av teknologiske hjelpemidler (parAbel) for å bedre læring i realfag for den videregående skolen. (Article in norwegian) Artikler om høgskolepedagogikk, HiA 2005.

[16] Oersted Medal Lecture 2007: Interactive simulations for teaching physics: What works, what doesn't, and why, C.E. Wieman, K.K. Perkins, W.K. Adams, American Journal of Physics, 76, 393 , May 2008. 